\title{
Anorexia in goldfish Carassius auratus infected with Trypanosoma danilewskyi
}

\author{
A. K. M. Nazrul Islam, Patrick T. K. Woo* \\ Department of Zoology, University of Guelph, Guelph, Ontario, Canada N1G 2W1
}

\begin{abstract}
Trypanosoma danilewskyi Laveran \& Mesnil, 1904 caused anorexia in experimentally infected goldfish Carassius auratus. This was most evident when the parasitemias were high. Some anorexic fish died of high parasitemias but those that survived the crisis returned to normal feeding.
\end{abstract}

\section{INTRODUCTION}

Trypanosoma danilewskyi Laveran \& Mesnil, 1904 is a pathogenic haemoflagellate which is not host specific (Woo \& Black 1984). The parasite has been isolated from common carp Caprinus carpio, crucian carp Carassius auratus gibelio, tench Tinca tinca and eel Anguilla sp. (Lom 1979). Its morphology and development in fish have been relatively well studied (Lom 1979, Lom et al. 1980, Paterson \& Woo 1984, Paulin et al. 1980, Skarlato et al. 1987, Woo 1981a).

Anorexia, which is decrease or cessation of food consumption (Morris et al. 1982, Symons 1985), has been associated with a number of gastrointestinal parasite infections (Morris et al. 1982, Crompton 1984 , Symons 1985, Holmes 1987). It has also been reported in mammalian trypanosomiasis (Koberle 1968, Holmes 1987) and piscine cryptobiosis (Li \& Woo 1991, Thomas \& Woo 1991). In contrast, there was increased food intake in laboratory rats inoculated with Trypanosoma lewisi homogenate (Lincicome 1971). Little is known about the effects of trypanosome infection on food consumption in fish. The present study was undertaken to carefully examine this relationship.

\section{MATERIALS AND METHODS}

The strain of Trypanosoma danilewskyi used was initially isolated from crucian carp. It was morphologically characterized, cryopreserved and maintained in goldfish Carassius auratus by blood inoculation (Woo

\footnotetext{
- Author for correspondence
}

$1981 \mathrm{a}, \mathrm{b}$ ). Goldfish (average $7.35 \mathrm{~g} ; 4.70$ to $10.65 \mathrm{~g}$ ) were bought from a local supplier and maintained at 20 $\pm 0.5^{\circ} \mathrm{C}$ in tap water in $50 \mathrm{l}$ glass aquaria (maximum 35 fish per aquarium). Fish were acclimatized to laboratory conditions for at least 3 to 4 wk before being used.

Fish were fed daily at about the same time with Martin's $83 \mathrm{G}$ salmonid pellets until satiated. Small pellets (ca $0.0025 \mathrm{~g}$ each) were prepared by grinding the pellets and grading them through sieves of 1.70 and $0.95 \mathrm{~mm}$ mesh. The fine portion $(<0.9 \mathrm{~mm}$; which floats) was discarded using the second sieve $(0.95 \mathrm{~mm}$ mesh). A pilot study indicated this pellet size (i.e. between 0.9 and $1.7 \mathrm{~mm}$ ) was acceptable to the fish. Food was presented to goldfish in an aquarium with a clean bottom. Pellets were first soaked in water for 5 to $10 \mathrm{~s}$ so that they sank readily. Fish were allowed $3 \mathrm{~min}$ to pick up the pellets. Feeding was stopped when 1 or 2 pellets remained on the bottom for more than $3 \mathrm{~min}$.

The caudal peduncle of an infected fish was severed after being killed by exposure to an overdose of MS 222. Blood was collected in heparinized haematocrit centrifuge tubes or in heparinized $1 \mathrm{ml}$ syringes. The number of parasites in the blood was determined using a Bright Line Haemocytometer (Archer 1965). If the number was too low for the leucocyte-count method, blood was drawn into a microhaematocrit centrifuge tube, sealed at one end with Critoseal and centrifuged at $13000 \times g$ for $4 \mathrm{~min}$ in a microhaematocrit centrifuge. The parasites at the junction of the plasma and buffy coat were counted under a microscope (Woo 1969).

Experiments were designed to investigate the effects of infection on food consumption. Parasitemias in experimental groups were inferred by bleeding fish from another infected group maintained under similar 
conditions to the 2 experimental groups (infected and uninfected). For analysis, total food consumed per day was converted to food consumed per g body weight of fish per day. Student's $t$-tests were used to compare food consumed by infected and uninfected fish. In the second experiment regression was used to determine the relationship between parasitemias and food consumption.

Experiment I. 30 fish of approximately similar size and weight were divided into 2 groups (15 fish each; Group A: total weight $91.72 \mathrm{~g}$, Group B: total weight $89.5 \mathrm{~g})$. Each group was maintained in a separate aquarium, fed at approximately the same time every day and amount of food consumed recorded. A third group (Group $C$ with 60 fish) was kept in 2 aquaria and fed as above. The amount of food consumed was not recorded in Group C. After 3 wk each fish in Groups A and $C$ was inoculated intraperitoneally with 20000 parasites; fish in Group B were inoculated with similar volume of saline. Five fish from Group $C$ were killed each week and parasitemias determined. Total weights (Groups A and B) were recorded each week for 9 wk.

Experiment II. The study was repeated with (a slightly different experimental design) 2 groups of fish; one group consisted of 15 and the other 30 fish (Group D). The group of 15 fish was divided into 6 subgroups, 3 of which consisted of 3 fish each and 3 of 2 fish each. The subgroups consisting of 3 fish each were infected ( $A$ /ex, $B / e x$, and $C / e x)$ and those with 2 fish were uninfected controls $(\mathrm{A} / \mathrm{CO}, \mathrm{B} / \mathrm{co}$, and $\mathrm{C} / \mathrm{CO})$. A substitute fish was added to the infected group to replace any fish which died. Three $50 \mathrm{l}$ aquaria were partitioned into 2 compartments with a net. One compartment contained control fish and the other infected fish. Fish were allowed to adjust to the system and technique of food presentation for $1 \mathrm{wk}$. Then fish from $\mathrm{A} / \mathrm{ex}, \mathrm{B} / \mathrm{ex}$, and C/ex and Group D were each inoculated intraperitoneally with trypanosomes (30000 parasites per fish). Control groups $(\mathrm{A} / \mathrm{CO}, \mathrm{B} / \mathrm{CO}$, and $\mathrm{C} / \mathrm{CO}$ ) were inoculated with Ringer's solution. Fish in all groups were fed until they stopped taking food. The experiment lasted $38 \mathrm{~d}$ and amount of food consumed and body weight of the fish were recorded at $7,12,17,22,27,32$, and $38 \mathrm{~d}$ after infection. Three fish from Group D were bled each day to determine parasitemias.

\section{RESULTS}

\section{Experiment I}

Food consumption of the 2 groups (A and B) was not significantly different for $3 \mathrm{wk}$ before fish were inoculated. After inoculation the infected group (A) consumed less food ( $\mathrm{mg} \mathrm{g}^{-1}$ body wt $\mathrm{d}^{-1}$ ) than the uninfected group (B) (Fig. 1). Decreased food consumption was related to the parasitemia which increased until the 6 th wk (significant at $\mathrm{p}<0.05$ when compared with 1 st wk parasitemia) and decreased through the last $3 \mathrm{wk}$ post-infection (parasitemia not significantly different from 1st wk) (Fig. 1).

Food consumption of infected fish during the first 6 wk post-infection was significantly lower $(p<0.01)$ than that in the uninfected fish. The anorexia coincided with parasitemias during that period. There was no significant difference in food consumption during the last $3 \mathrm{wk}$ of infection $(7 \mathrm{th}, 8 \mathrm{th}$, and 9th wk post-infection) between these 2 groups.

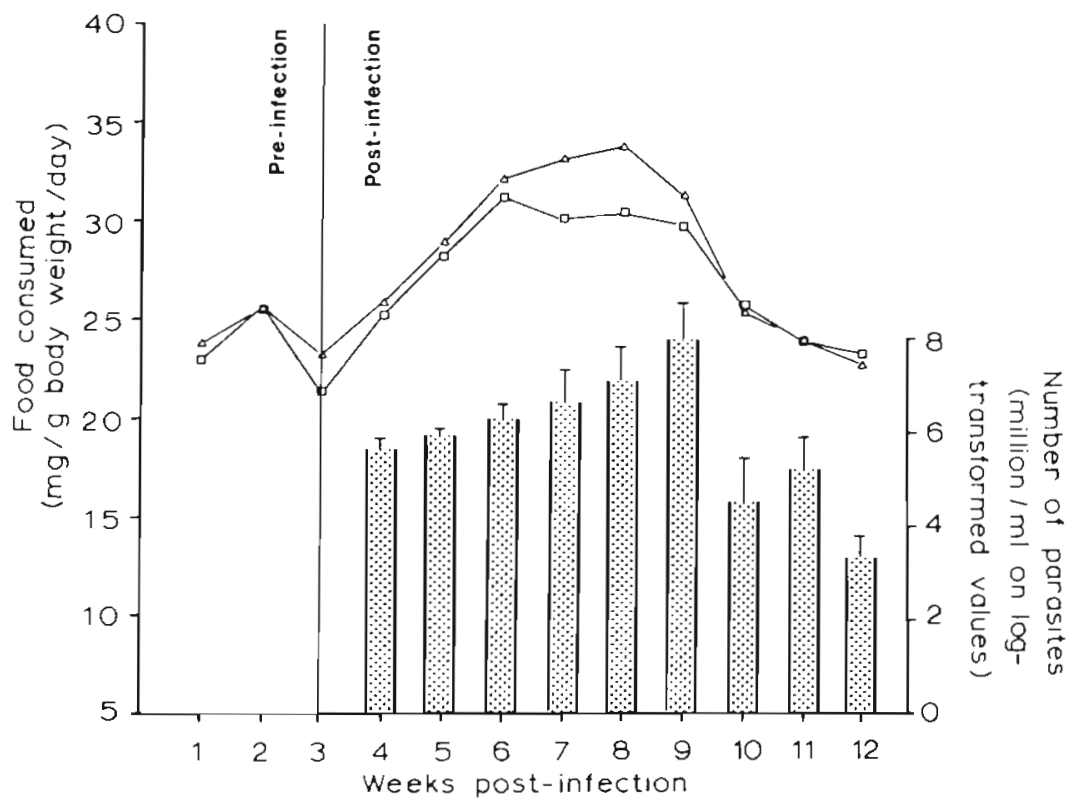

Fig. 1 Carassius auratus. Food consumption in uninfected and Trypanosoma danilewskyi infected goldfish. Para. sitemias (mean with standard error of the mean) in another group of infected fish are shown by bars (Expt I). ( $\triangle$ ) Food consumed by uninfected fishi (G) food consumed by infected fish 


\section{Experiment II}

As a group, infected fish consumed less food than uninfected fish (Fig. 2, Table 1). At the 17th and 22nd days post-infection, infected fish consumed significantly less food than uninfected fish (Fig. 2, Table 1). The decline in food consumption in infected fish coincided with high parasitemias. Parasitemias were significantly higher at the 12 th, 17 th, and 22 nd days postinfection when compared with that on the 7 th day (Fig. 2).

Weight gain in the infected fish (percent weight gain per fish) was less than uninfected fish, but was not statistically significant compared to that in uninfected fish. Cessation or reduction in food intake was observed in some fish during high parasitemias (12 to $22 \mathrm{~d}$ post-infection). These fish usually isolated themselves from the group and some of them died (with massive parasitemias) $12 \mathrm{~h}$ to $7 \mathrm{~d}$ later. Fish that survived the infection resumed normal feeding

\section{DISCUSSION}

In both experiments, food consumption by infected goldfish was greatly reduced when parasitemias were high. Thomas \& Woo (1991) reported anorexia in rainbow trout with cryptobiosis and showed that it contributed to immunodepression. Food intake may also be reduced in mammalian trypanosomiasis (Holmes 1987). Several causes of anorexia have been suggested
Table 1. Carassius auratus. Food consumed by uninfected goldfish and goldfish infected with Trypanosoma danilewskyi (Expt II)

\begin{tabular}{|c|c|c|c|}
\hline $\begin{array}{l}\text { Days } \\
\text { post- } \\
\text { infection }\end{array}$ & \multicolumn{2}{|c|}{$\begin{array}{l}\text { Average food consumed } \\
\left.\text { (mg g } \mathrm{g}^{-1} \text { body wt } \mathrm{d}^{-1}\right)\end{array}$} & 't'-value \\
\hline 0 & 1.5183 & 1.5639 & $1.179^{\mathrm{ns}}$ \\
\hline 7 & 1.5352 & 1.5612 & $1.357^{\mathrm{ns}}$ \\
\hline 12 & 1.5841 & 1.4341 & $1.608^{\mathrm{ns}}$ \\
\hline 17 & 1.5837 & 1.3950 & $2.843^{\circ}$ \\
\hline 22 & 1.6059 & 1.3467 & $2.887^{\circ}$ \\
\hline 27 & 1.5957 & 1.4947 & $0.829^{n s}$ \\
\hline 32 & 1.5282 & 1.5710 & $0.549^{\text {ns }}$ \\
\hline 38 & 1.5710 & 1.5759 & $0.316^{\mathrm{ns}}$ \\
\hline $0-38$ & 1.5652 & 1.4725 & $2.752^{\cdots}$ \\
\hline \multicolumn{4}{|c|}{$\begin{array}{l}\text { Data are log transformed. } \\
\text { ns Not significant; }{ }^{*} \text { significant at } 5 \% \text { level; }{ }^{*} \text { significant } \\
\text { at } 1 \% \text { level }\end{array}$} \\
\hline
\end{tabular}

(Crompton 1984, Symons 1985, Holmes 1987) e.g. low motility of food through the intestine, disruption of gut mucosa (usually associated with pathogenic intestinal parasites) thereby impairing digestion and absorption, increase in cholecystokinin (an alimentary hormone that may reduce appetite). It was shown that changes in concentration of cholecystokinin in the brain and plasma elicit satiety (Baile et al. 1986). Changes in plasma level of gastrin in a parasitized animal may also result in altered food intake (Titchen 1982). Like cholecystokinin the gastrin may affect feeding by
Fig. 2. Carassius auratus. Food consumption (mean with SEM) in uninfected and Trypanosoma danilewskyi infected goldfish. Parasitemias (mean with SEM) in another group of infected goldfish are shown by bars (Expt II). (L) Food consumed by uninfected fish; (ㅁ) food consumed by infected fish

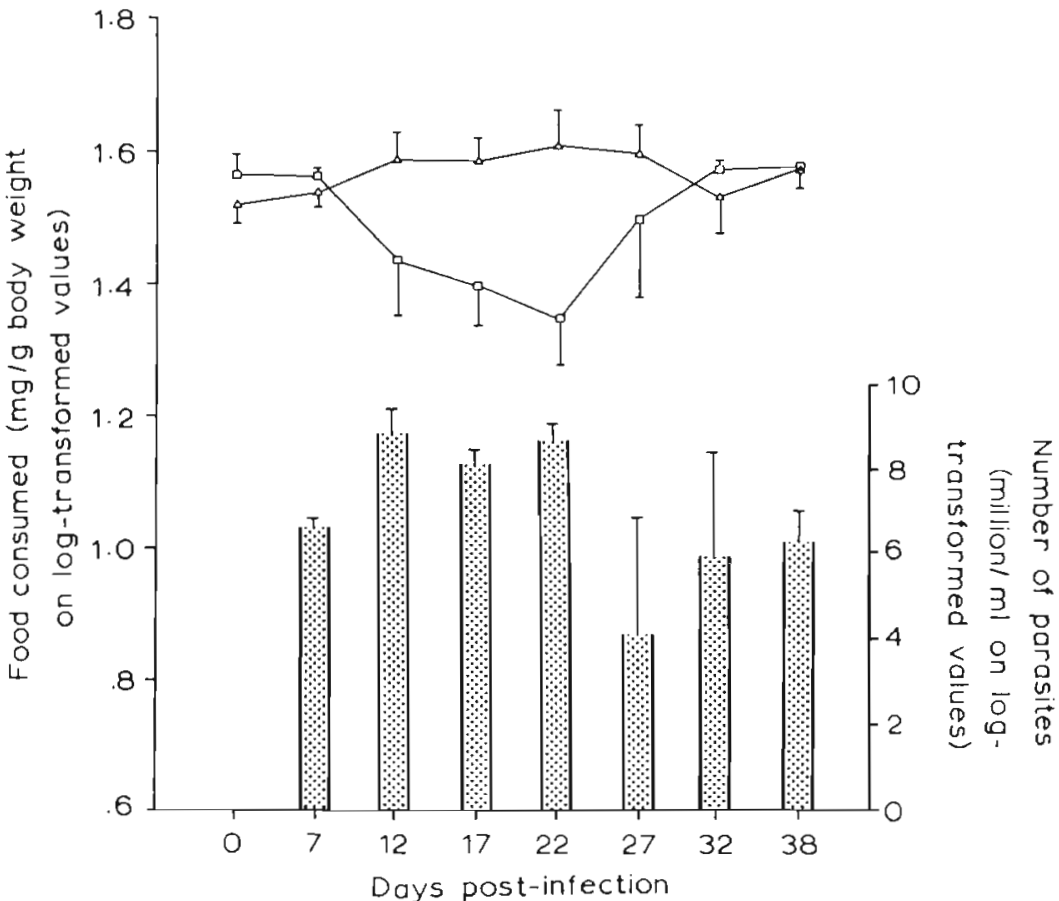


peripheral action or action via the central nervous system (Baile et al. 1986). McCarthy et al. (1985) reported depression in food intake caused by interleukin-1, a protein synthesized and released by phagocytes in response to infection in an immune reaction (Dinarello 1984. Marrack \& Kappler 1986). They proposed that this may be due to increased renal excretion and changes in gastric motility caused by interleukin-1. We suggest that interleukin-1 may be an important contributing factor in anorexia-related diseases caused by pathogenic haemoflagellates (e.g. Trypanosoma, Cryptobia). Cryptobia salmositica of salmonids is engulfed by macrophages during infections (Woo 1979) and it was suggested that phagocytosis plays a vital role in controlling cryptobiosis (Woo 1979, Jones \& Woo 1987. Thomas \& Woo 1990).

Anorexia retards growth (Crompton 1984, Symons 1985 ) and was shown to be a contributing factor in retarding growth in trout infected with Cryptobia salmositica (Li \& Woo 1991). In the present study, however there was no significant decrease in weight in infected fish. Anorexic fish either died from the infection or survived the crisis and returned to normal feeding.

Acknowledgement. This study was supported by a grant from the Natural Sciences and Engineering Research Council of Canada to P.T.K.W.

\section{LITERATURE CITED}

Archer, R. K. (1965). Haematological techniques for use on animals. Blackwell Scientific Publications, Oxford

Baile, C. A., Mclaughlin, C. L., Della-Fera, M. A. (1986). Role of cholecystokinin and opioid peptides in control of food intake. Physiol. Rev. 66: 172-234

Crompton, D. W. T (1984). Influence of parasitic infection on food intake. Fed. Proc. Am. Soc. Exptl Biol. 43: 239-245

Dinarello, C. A. (1984). Interleukin-1. Rev. infect. Dis. 6: 51-95

Holmes, P. H. (1987). Pathophysiology of parasitic infections. Parasitol. 94: 529-551

Jones, S. R. M., Woo, P. T K. (1987). The immune response of rainbow trout, Salmo gairdneri Richardson, to the haemoflagellate, Cryptobia salmositica Katz, 1951. J. Fish Dis. 10: $395-402$

Koberle, F. (1968). Chagas' disease and Chagas syndromes: the pathology of American trypanosomiasis. In: Dawes, B (ed.) Advances in parasitology. Vol.6. Academic Press, London, p. 63-116

Li, S., Woo, P. T. K. (1991). Cryptobia salmositica in Oncorhynchus mykiss: anorexia reduces the severity of cryptobiosis in salmonids. J. Parasit. (in press)

Lincicome, D. R. (1971). The goodness of parasitism: a new

Responsible Subject Editor: W. Körting, Hannover, Germany hypothesis. In: Cheng, T. C. (ed.) Aspects of the biology of symbiosis. University Park Press, Baltimore, p. 139-227

Lom, J. (1979). Biology of trypanosomes and trypanoplasms of fish. In: Lumsden, W. H. R., Evans, D. A. (eds.) Biology of the Kinetoplastida, Vol.2. Academic Press, London, p. $269-337$

Lom, J., Paulin. J. J., Nohynkova, E. (1980). The fine structure of the fish trypanosome, Trypanosoma danilewskyi: I. Presence of a cytopharyngeal complex in bloodstream trypomastigotes. Protistologica 16: 365-373

Marrack, P., Kappler, J. (1986). The T cell and its receptor Scient. Am. 254: 36-45

McCarthy, D. O., Kluger, M. J., Vander, A. J. (1985). Suppression of food intake during infection: is interleukin-1 involved? Am. J. clin. Nutr. 42: 1179-1182

Morris, M. L., Teeter, S. M., Doering, G. G. (1982). Anorexia: a commentary on nutritional management of small animals M. Morris Associates, Topeka, Kansas

Paterson, W. B., Woo, P. T K. (1984). Ultrastructural studies on mitosis in Trypanosoma danilewskyi (Mastigophora: Zoomastigophorea). Can. J. Zool. 62: 1167-1171

Paulin, J. J., Lom, J., Nohynkova, E. (1980). The fine structure of Trypanosoma danilewskyi: II. - Structure and cytochemical properties of the cell surface. Protistologica 16: $375-383$

Skarlato, S. O., Lom, J., Nohynkova, E. (1987). Fine structural morphology of the nucleus of Trypanosoma danilewskyi (Kinetoplastida, Trypanosomatina) during mitosis. Arch. Protistenk. 133: 3-14

Symons, L. E. A. (1985). Anorexia: occurrence, pathophysiology, and possible causes in parasitic infections. In: Baker, J. R., Muller, R. (eds.) Advances in parasitology, Vol. 24. Academic Press, London, p. 103-133

Thomas, P. T., Woo, P. T K. (1990). In vivo and in vitro cell. mediated immune responses of Salmo gairdneri against Cryptobia salmositica (Sarcomastigophora: Kinetoplastida). J. Fish Dis. 13: 423-433

Thomas, P. T., Woo, P. T K. (1991). Anorexia in rainbow trout, Oncorhynchus mykiss (Walbaun), infected with Cryptobia salmositica (Sarcomastigophora: Kinetoplastida): its onset and contribution to immunodepression. J. Fish Dis. (in press)

Titchen, D. A. (1982). The role of hormones in the reactions of the host to enteric parasites. In: Mettrick. D. F., Desser, S. S. (eds.) Parasites - their world and ours. Elsevier Biomedical Press, Amsterdam, p. 245-247

Woo, P. T. K. (1969). The haematocrit centrifuge for the detection of trypanosomes in blood. Can. J. Zool. 47: 921-923

Woo, P. T K. (1979). Trypanoplasma salmositica: experimental infections in rainbow trout, Salmo gairdneri. Exptl Parasit. $47: 36-48$

Woo, P. T. K. (1981a). Trypanosoma danilewskyi: a new multiplication process for Trypanosoma (Protozoa: Kinetoplastida). J. Parasitol. 67: 522-526

Woo, P. T. K. (1981b). Acquired immunity against Trypanosoma danilewskyi in goldfish, Carassius auratus. Parasitology 83: 343-346

Woo, P. T K., Black, G. A. (1984). Trypanosoma danilewskyi: host specificity and host's effect on morphometrics. J. Parasitol. $70: 788-793$

Manuscript first received: March 12, 1990

Revised version accepted: April 10, 1991

(Several months delay due to loss of manuscript in the mail) 